\title{
Guidelines and Asthma: Some Considerations for Third World Countries
}

\author{
Carlos Albarran ${ }^{1}$, Arnaldo Capriles Hulett ${ }^{1}$, Mehtap Haktanir Abul2* and James Caplin ${ }^{3}$ \\ 1 Unidad de Alergologia, Hospital San Juan de Dios, Caracas, Venezuela \\ ${ }^{2}$ Department of Pediatric Allergy and Immunology, Karadeniz Technical University, Turkey \\ ${ }^{3}$ Allergy and Asthma Center, Corpus Christi, Texas, USA
}

Significant efforts have been devoted by the world medical establishment in the elaboration of Evidence Based asthma Guidelines, widely recognized as an important contribution to the health of patients and families afflicted with this high impact respiratory illness. When appropiately implemented, improvement in clinical outcomes as well as Quality of Life (QoL) has been shown. Inhaled steroids are the mainstream of these treatments [1].

However, the implementation of these guidelines has been fraught with many disappointments [2,3]. Observations and reports from all over the globe [4], with occasional exceptions, have confirmed these drawbacks. An opportunity is now open to think more creatively in this regard [5].

The crucial issue to be considered here is assesing the difference between two inter-related basic treatment concepts [6]; one is the clinical efficacy and the other one is the clinical effectiveness. Efficacy is a term in common use around clinical trial scenarios: a highly selected patient population is submitted to a specific treatment, usually in a double blind placebo-controlled manner. Characteristically, these trials show an intrinsic increased adherence to medications. Outcomes are measured on the basis of how many patients "get treated" vs. how many of these treated patients "get controlled", as is the case for asthma. In contradistinction, effectiveness relates to the public health scenario: how many patients are there with asthma vs how many of those patients are controlled. Here, adherence issues pertain to the real life scenario.In essence, you may have the best treatment available but if it is not delivered in a comprehensive way, it ends up being with not much worth.For example, if such treatments also have severe adverse effects and/or require extensive health education for proper administration and/or have important limitations because of taste (the case for children), then treatment efficacy is downplayed [6].

Physicians in general and to some extent public health officials, at least in some areas of the world, consider validated guidelines as the ultimate word on a specific subject (and deservedly so). Any deviations from "dogma" is considered as heresy, even though in GINA Guidelines explicit recommendations addressing this issue are made [1].

In fact, such document should be adapted to local/regional real - life scenarios and necessarily it should not be followed to the letter $[1,5]$. Then,deviations from Guidelines should not be discouraged. The above argument opens two areas of great interest; one refers to inhaled steroids and the other applies to the context of their use. We would like to use Venezuela as a fertile ground for this discussion [7]. Venezuela is a tropical country located 10 degrees above the equator in the most northern part of South America; it has close to 30 million mostly young $(<15 \mathrm{y} / \mathrm{o})$ inhabitants, living in crowded urban (slums) environments $(>90 \%)$ and under variable conditions of poverty $(>80 \%$ Graffar's D and E). According to ISAAC, asthma prevalence run among the highest $(20 \%)$ in Latin American countries, and with a significant component of severity. The above finds expression in the recurrent asthma exacerbations that have increasingly plagued (with rates up to 4 fold) the ambulatory facilities of the Ministry of Health $(\mathrm{MoH})$ for the past 25 years [7]. These facilities handle the health needs of our urban and poor majority; the most affected segment of the population with increased levels of asthma prevalence [8].
Acute asthma in these facilities ranks as the second cause of consultations, after the so-called "viral syndrome "; this second place is often alternated with diarrheas [8].

More than 1 million acute exacerbations/year among our 30 million inhabitants surpass at least more than five times those reported in the United States [9], with more than 10 times our number of inhabitants. Exacerbations predominantly occur during night hours, when the above mentioned ambulatory facilities are closed, so patients have to go outside their community to receive nebulizations,something fraught with security problems among other hardships [7]. It is logical to assume that we are dealing with a pandemic of asthma exacerbations, with little conscience, if any, for disease control. How have we approached this public health problem over the years? There is a National Asthma Control Program, following GINA guidelines, that relies on inhaled steroids (Beclomethasone) as the first line treatment. It was last revised in 1998 and the present state of affairs informs us of its poorly implementation [5,7]. To say the least, the use of inhaled medications is cumbersome; ample evidence from existing literature confirms this [10]. Adherence and cost are another significant problems [11]. Use of these medications in the context of our urban (slum) and poor majorities demands of significant educational components while addressing cultural factors, like fears related to their use [12].

Can an alternative simpler and effective approach decrease the high impact from recurrent exacerbations? Can drifting from GINA guidelines is a worthwhile endeavor? With this in mind we designed the EESSO * strategy [5] and decided to test it in the field. Of the available second line treatments, oral Montelukast (MLK) jumps at the fore front. For the context we intended it for shows the following advantages:

a. Minimal, if any, adverse effects. It is administered once a day.

b. MLK seems to perform better in a tobacco exposed environment [13]; $60 \%$ of our slum urban homes report tobacco exposure [7].

c. MLK is as effective as inhaled steroids to curtail recurrent exacerbations, for children as well as for adults [14-16].

d. MLK is orally administered,hence,almost no education is needed for proper administration.

e. MLK has a significant effect on rhinitis. Disregarding the upper airway may have significant impact on outcomes,like exacerbations and level of control [17].

*Corresponding author: Abul Mehtap H, Department of Pediatric Allergy and Immunology, Karadeniz Technical University, Turkey, Tel: 361-888-6782; E-mail: mhabul@texaschildrens.org

Received December 23, 2014; Accepted April 06, 2015; Published April 10, 2015

Citation: Albarran C, Hulett AC, Abul MH, Caplin J (2015) Guidelines and Asthma Some Considerations for Third World Countries. J Pulm Respir Med 5: 253. doi:10.4172/2161-105X.1000253

Copyright: (c) 2015 Albarran C, et al. This is an open-access article distributed under the terms of the Creative Commons Attribution License, which permits unrestricted use, distribution, and reproduction in any medium, provided the original author and source are credited. 
f. MLK has no interaction with other medications, for the most part, and has a pleasant taste (important for children).

g. In regards to cost, MLK patent expiration this past year offers clear opportunities [18]. A formulation that combines a non sedating antihistamine+MLK (available in some countries), might be another innovative and creative way that ought to be seriously considered.

We carried on a real-life, double blind placebo controlled study [5] on a slum population of Caracas,reflecting the living conditions of $50 \%$ of its inhabitants, and likely of Venezuela [7]. Eighty eight patients with physician diagnosed asthma were recruited (half were children $<12 \mathrm{y} / \mathrm{o}$ ). These patients relied basically on rescue treatments administered at the mentioned $\mathrm{MoH}$ facilities,and given in the form of nebulizations of a combination of fenoterol+ipatroprium bromide [5]. Their demographics were recordedand allergy status determined by way of prick skin testing. Pulmonary function tests were performed with a Wright's Peak Flow Meter (WPFM, L/min),with a pre and post $400 \mathrm{mcg}$ albuterol reversibility assessment; Asthma Control test (ACT) according to age and a single page minimal pictorial education was given. Follow up visits were scheduled every three months over the period of a year in addition to monthly phone calls. There are practically no homes in Venezuela lacking cell phone communication (there are over 16 million cell phone lines). This opportunity was used to remind patients to take the medication and to register the number of times they had to go to the $\mathrm{MoH}$ ambulatory facilities to be nebulized for an exacerbation. They were questioned in detail about it during follow up visits. Adherence was estimated by counting of of empty blisters, for both Placebo (PBO) and MLK, and found to be greater than $80 \%$. The first three and six months follow up results revealed a significant difference in recorded patient asthma exacerbations cared for at the $\mathrm{MoH}$ facilities; $\mathrm{p}$ values were $\mathrm{p}:<004$ and $\mathrm{p}$ : $<003$, between PBO and, respectively.

This trend favoring MLK remained for the rest of the year,but patient attrition did not allow for significant numbers. In summary, and pending confirmation with larger number of patients from similar contexts, the EESSO strategy could pose as an alternative to a GINA guidelines approach (based on the use of inhaled medications). It could be started,due to it's simplicity, during the only contact an asthmatic patient has with the health system, such as while suffering an exacerbation; crowded emergency rooms/or ambulatory facilities could then be used for initiating this approach. A structured minimal oral education plus a one page written pictorial educational material can easily dispensed. SMS text messages could be a useful adjunct to encourage compliance and follow-up visits. If patients, continue to have recurrent exacerbations in spite of adequate use of MLK, a referral to an asthma clinic can be more in tune with proper allocation of resources.

The world's tendency [19] to live in impoverished slums summons us to face new challenges in the delivery of comprehensive asthma care to this majoritarian and impoverished urban communities. If we are to focus on exacerbations and their great impact on health systems, the EESSO strategy could be one (among many), to look for. Asthma, urban environments/slums and poverty are interacting elements that need to be addressed in a contextualized way. Inaction is not an option if we are to deal with the social determinants of asthma.

${ }^{*}$ EESSO (in spanish it means: " that's it", "that is what it is").

E stands for Efficacy

E stands for Economical (low cost)

$S$ stands for Social

$S$ stands for Safety

O stands for oral

\section{References}

1. Bousquet J, Clark TJ, Hurd S, Khaltaev N, Lenfant C, et al. (2007) GINA guidelines on asthma and beyond. Allergy 62: 102-112.

2. Boulet LP, Phillips R, O'Byrne P, Becker A (2002) Evaluation of asthma control by physicians and patients: comparison with current guidelines. Canadian respiratory journal: journal of the Canadian Thoracic Society 9: 417-423.

3. Horne R, Price D, Cleland J, Costa R, Covey D, et al. (2007) Can asthma control be improved by understanding the patient's perspective? BMC Pulm Med 7: 8.

4. Al-Jahdali $\mathrm{HH}$, Al-Omar AM, Al-Moamary MS, Al-Duhaim AS, Al-Hodeib AS, et al. (2004) Implementation of the national asthma management guidelines in the emergency department. Saudi Med J 25: 1208-1211.

5. Capriles Hulett A, Yibirin MG, Garcia A, Hurtado D (2014) Montelukast for the high impact of asthma exacerbations in Venezuela: a practical and valid approach for Latin America? World Allergy Organ J 7: 20.

6. Searson G, Engelson ES, Carriero D, Kotler DP (2014) Treatment of chronic hepatitis $C$ virus infection in the United States: some remaining obstacles. Liver international: official journal of the International Association for the Study of the Liver 34: 668-671.

7. Hulett AC, Yibirin MG, Brandt RB, Garcia A, Hurtado D, Puigbo AP (2013) Home/social environment and asthma profiles in a vulnerable community from Caracas: lessons for urban Venezuela? The Journal of asthma: official journal of the Association for the Care of Asthma 50: 14-24.

8. Sánchez-Borges M, Capriles-Hulett A, Caballero-Fonseca F (2011) Asthma care in resource-poor settings. World Allergy Organ J 4: 68-72.

9. Jackson DJ, Sykes A, Mallia P, Johnston SL (2011) Asthma exacerbations: origin, effect, and prevention. J Allergy Clin Immunol 128: 1165-1174.

10. Inhaler Error Steering Committee, Price D, Bosnic-Anticevich S, Briggs A Chrystyn H, et al. (2013) Inhaler competence in asthma: common errors, barriers to use and recommended solutions. Respir Med 107: 37-46.

11. Bateman ED (2014) Treatment adherence in asthmatic patients: the last frontier? J Allergy Clin Immunol 134: 1269-1270.

12. Cruz AA, Bateman ED, Bousquet J (2010) The social determinants of asthma Eur Respir J 35: 239-242.

13. Price D, Popov TA, Bjermer L, Lu S, Petrovic R, et al. (2013) Effect of montelukast for treatment of asthma in cigarette smokers. J Allergy Clin Immunol 131: 763-771.

14. Price D, Musgrave SD, Shepstone L, Hillyer EV, Sims EJ, et al. (2011) Leukotriene antagonists as first-line or add-on asthma-controller therapy. N Engl J Med 364: 1695-1707.

15. Ducharme FM, Noya FJ, Allen-Ramey FC, Maiese EM, Gingras J, et al (2012) Clinical effectiveness of inhaled corticosteroids versus montelukast in children with asthma: prescription patterns and patient adherence as key factors. Current medical research and opinion 28: 111-119.

16. Wu AC, Li L, Fung V, Kharbanda EO, Larkin EK, et al. (2014) Use of leukotriene receptor antagonists are associated with a similar risk of asthma exacerbations as inhaled corticosteroids. The journal of allergy and clinical immunology In practice 2: 607-613.

17. Ponte EV, Franco R, Nascimento HF, Souza-Machado A, Cunha $S$, et al. (2008) Lack of control of severe asthma is associated with co-existence of moderate-to-severe rhinitis. Allergy 63: 564-569.

18. Merck - 10 Largest U.S. Patent Losses

19. Unger A (2013) Children's health in slum settings. Arch Dis Child 98: 799-805. 